\title{
A NEW GENUS OF PERLIDAE
}

\author{
By NATHAN BANKS \\ Museum of Comparative Zoology, Cambridge, Mass.
}

The sternal structures of Perlidæ have not been investigated as fully as some other parts of their structure. In examining Acroneuria for some structure to distinguish the females from other Perlidæ, I noticed that in two of our species the grooves on the meso- and metasterna were different from other species of Acroneuria. In the figures I have shown the differences. In the typical Acroneuria the anterior grooves are widely devergent, in A. pacifica they are short and nearly parallel. This sternal difference is correlated with the broader ocellar triangle, and the position of the lateral bosses, as well as in the last segment of the male. I shall, therefore, make A. pacifica the type of a new genus.

\section{Hesperoperla gen. nov.}

Anterior meso- and metasternal grooves short and nearly parallel; the ocellar triangle plainly broader than long; the lateral bosses on a level with the anterior ocellus; in the male the last ventral segment has a nearly quadrangular boss instead of the usual elliptic or rounded one; in the fore wing the second anal vein is frequently forked (rarely in Acroneuria). In Acroneuria the ocellar triangle is as long as broad, and the lateral bosses are higher. In Beloneuria the anterior sternal grooves are somewhat as in Hesperoperla, but curve outward more, but not nearly as much as in Acroneuria; the lateral bosses are higher, although the ocellar triangle is broader than long; the peculiar structure of the last ventral segment of the male in Beloneuria, somewhat like that of some Pteronarcys, will readily distinguish this genus, as well as the irregular apical venation.

Genotype: Acroneuria pacifica Bks. 


\section{Hesperoperla obscura sp. nov.}

In general structure much as in $H$. pacifica. Body brown to almost black, venter pale through the middle, some yellowish on head, anterior margin of head a little more projecting than in $H$. pacifica; sculpture of pronotum as in $H$. pacifica; last dorsal segment gently, evenly rounded; the ventral plate of female with a distinct median emargination.

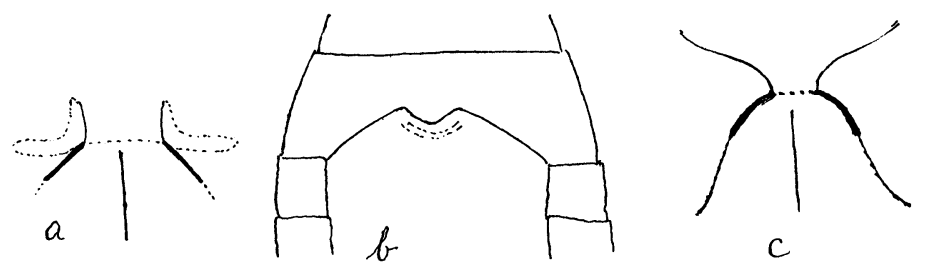

Fig. 1. a-Hesperoperla, mesosternal grooves; b-Hesperoperla obscura, ventral plate; c-Acroneuria, mesosternal grooves.

Wings less distinctly yellowish than $H$. pacifica, venation similar.

Expanse 48 to $50 \mathrm{~mm}$.

From Laggan, Alberta 22 July (Osburn coll.).

In $H$. pacifica Bks. the ventral plate of the female is rounded and entire; the head and pronotum more yellowish. Type, M. C. Z., no. 23223.

I believe that these grooves from the inner ends of the slits of the meso- and metanotum have an important bearing on the classification of the Perlidæ. They are present mostly in the old genus Perla, now much divided. In our fauna they are in Perla, Acroneuria, Togoperla, and Banksiella; in Asia they occur in Tylopyge, Oyamia, Kaminuria, Mesoperla, Niponiella, Kalidasia, and Schistoperla.

They are not present in Isogenus, Clioperla, Hydroperla, Perlesta, Isoperla, Perlinella, nor in Paraperla which I propose to put in a separate tribe, the Isogenini. They are not present in the Cloroperlini (Alloperla and Chloroperla), nor in the Peltoperlini, but are evident, though sometimes fainter, in the Neoperlini. The Peltoperlini have the middle part of the metasternum very much broader than in the other groups. 

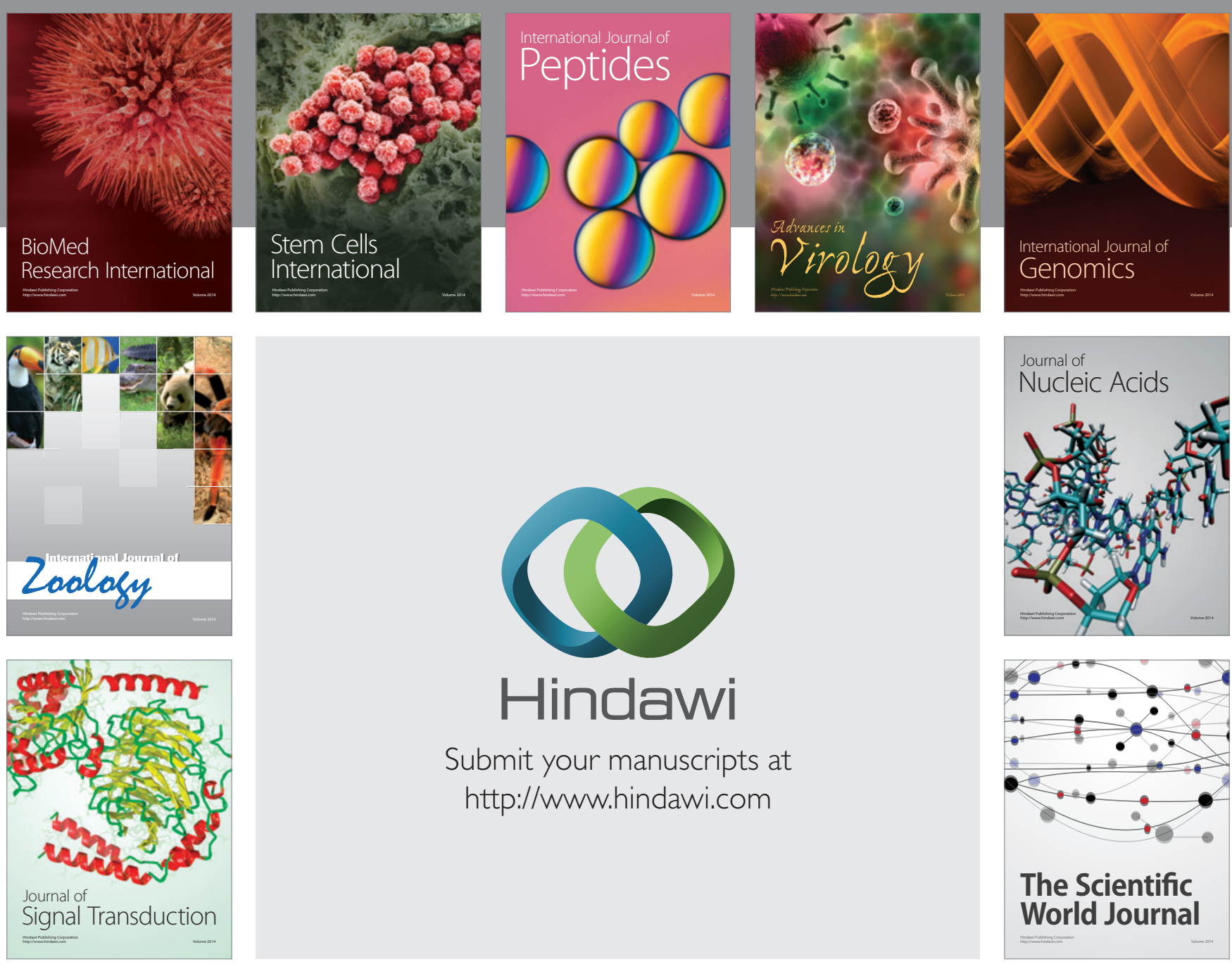

Submit your manuscripts at

http://www.hindawi.com
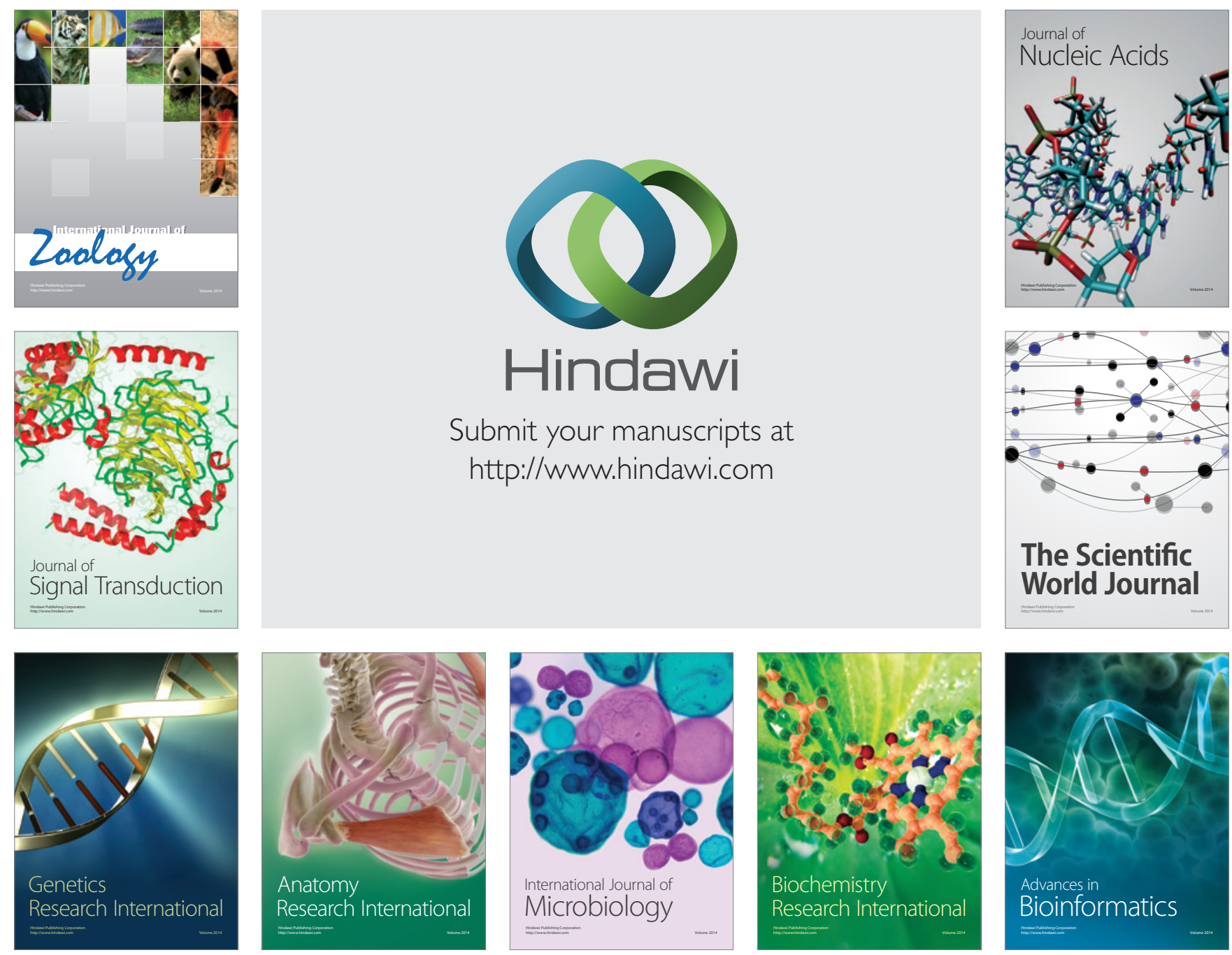

The Scientific World Journal
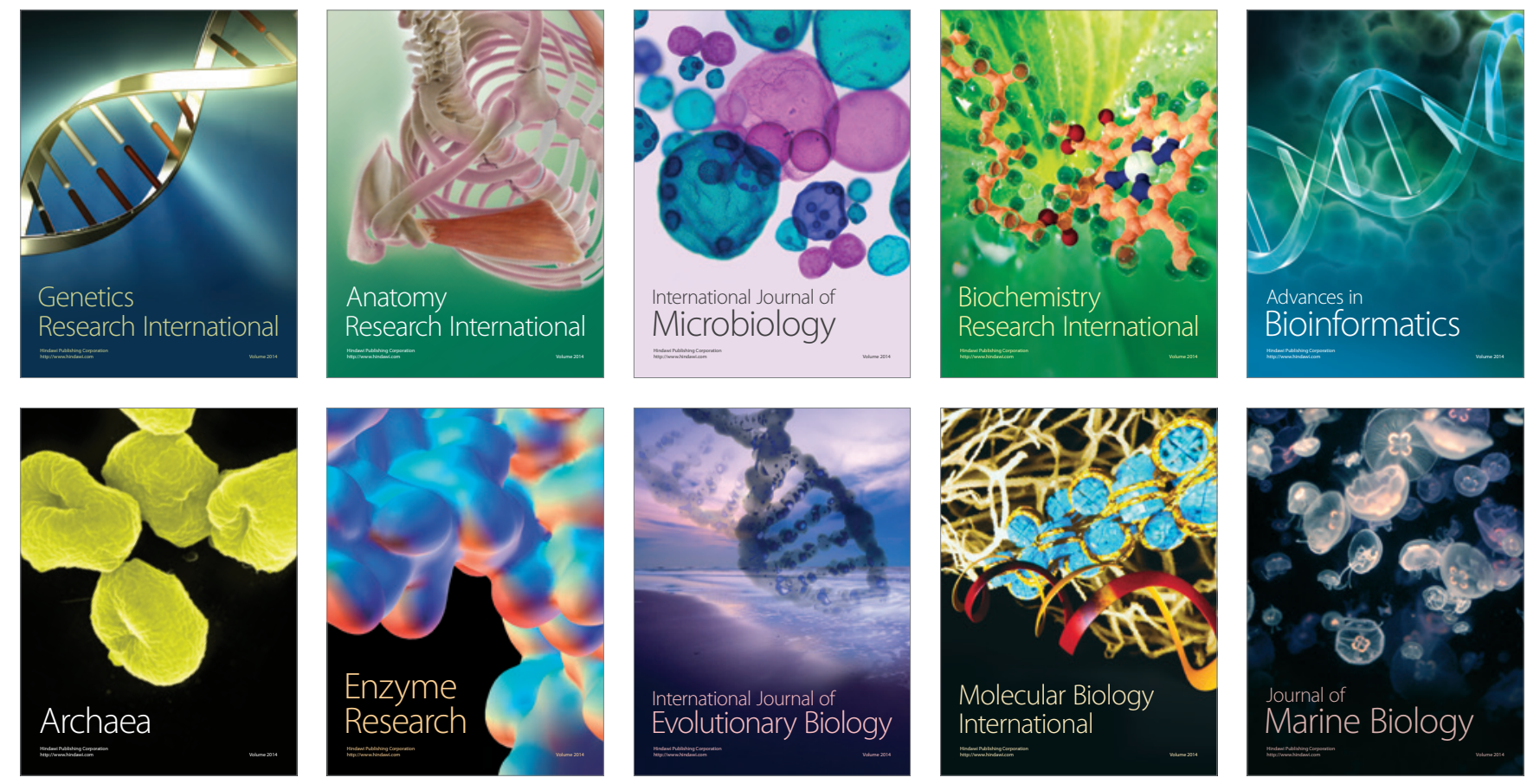